\title{
Evaluation of Safety and Health Conditions in Large Scale Construction Projects
}

\author{
Jalal Salek Zamankhani ${ }^{1}$
}

\begin{abstract}
In the past decade, a lot of studies and researches have been done on the problems concerning the management of safety and health in construction sites. But, there are very few studies discussing the issue in project environment from viewpoint of workers. Especially, safety and health management, which has been usually subject of the empiricism, is not considered deeply on the large scale construction sites in Iran. However, it is necessary to understand the quantitative mechanism of safety and health in project site to proceed the necessary management technique properly, and set up the suitable strategies by trade-off of risk and cost to reduce the safety and health risk during construction of the project. In this paper, employees of several large scale construction projects in metropolitan areas of Tabriz were randomly selected and were asked to respond the NOSACQ questionnaire. The results showed that safety and health management in large scale construction sites are relatively acceptable. Besides, the perception of safety and health was found to have no special association with age, work experience, education, but instead the creation of a safety climate depends on the approach of people higher in the organizational hierarchy of the project.
\end{abstract}

Keywords: construction, health, safety, sustainability.

\section{Introduction}

In the current sustainable development context, the construction safety and health is particularly relevant due to its social and economic aspects. Nowadays, increased research and survey on the subject of sustainable construction safety and health is an emerging trend in the construction industry all over the world. The sustainable construction safety and health is a concept to sustain a construction worker's safety and health from start to finish of a single project, for each future project a worker is involved in, and during the worker's remaining lifetime after retirement, without any injuries or illnesses (Rajendran \& Gambatese, 2009).

On the other hand, the project management offices should operate the project in the uncertainties of environmental conditions, and control the risk of damage to safety and health of workers. The construction projects are becoming large-scale and complicated, how to process qualitative/quantitative analysis of project risks and how to deal with the results of project risks are more and more important for the stakeholders of project (Tsai et al., 2001).

However, management of safety and health has not been established as a theory on the construction site, and usually has been proceeded in empiricism by most of project managers. And, the viewpoints of the safety-related risks and the considerations of risk management from the engineers of construction sites are hardly discussed in Iran. 
Therefore, it is necessary to understand the current situation of project risks and the realities of risk management, and to develop the decision support system which can support the stakeholders of project to consider various risk strategies.

Since sustainable design and construction practices are primarily aiming at minimizing environmental and resource impacts, improving the health, safety and productivity of workers in a construction project, especially in urban environments is considered to be crucial for the achievement of sustainability. Construction work is among most hazardous and harmful occupations, and has approximately six times as many damage or fatalities per hour worked and twice as many disabling damages or injuries rather than manufacturing industry all over the world. In addition, safety and health of all workers involved in the project play an important role in achieving a sustainable socio-economic development in the construction industry.

The aims of this paper was to investigate and determine the important factors in successful sustainable construction safety and health in large scale projects, and to suggest the model of initial investigation for potential motivators to achieve sustainable construction safety and health in Iran.

\section{Literature Review}

Construction activities have a major impact on physical development, government policies, community activities and welfare programs. However, over their entire lifecycle, construction activities are also connected with the broader problems and issues affecting the environment, including global warming, deterioration of natural resources, climate change, ozone depletion, soil erosion, desertification, deforestation, eutrophication, acidification, loss of diversity, land pollution, and consumption of valuable resources such as fossil fuels, minerals and gravels (Pearce et al. 2012; EIA, 2014; Ahn et al., 2007; Roodman, 1995).

In an attempt to address these issues and problems, the building industry in many countries has begun to implement green building (sustainable architecture) methods and technologies. To achieve benefits of a green building, the project team needs to shift to more integrated processes in all phases of a building's life cycle (Larsson et al. 2009). Tasks in green building design and construction phase are not completed by a single action or entity but require a multidisciplinary team approach and the implementation of iterative processes during the building's design and construction. At the construction phase, careful attention must be devoted to both design strategies and construction opportunities for ensuring that a project is delivered in a sustainable fashion. To successfully implement green strategies and technologies during the construction phase, a range of green strategies and technologies can be deployed to achieve the goals of green building. Construction opportunities here include preconstruction services, minimizing site disturbance, erosion and sedimentation control, pollution prevention, sustainable site operation, construction waste management, indoor air quality management, green materials management, and commissioning, among others (Pearce et al. 2012; Frattari et al. 2012; Han Ahn et.al., 2016).

Most part of the studies related to safety and health management processes in construction projects have mainly discussed the body of knowledge in project 
management system, and the studies of contract relation are mainly discussing the reasonable allocation of responsibilities for the stakeholders of a construction project. Normally, these studies use the qualitative methods like influence diagram, game theory, AHP (analytic hierarchy process), etc. to identify the risks related to safety and health of human resources in construction projects.

But, most part of the studies on safety risk analysis technique are mainly discussing the cost overrun and schedule delay of the activities concerning the client and contractor of project. Normally, these studies use the quantitative methods like sensitive analysis, fuzzy theory, Monte Carlo simulation, etc. to build a model and simulate the probabilities and deviations for the realities and planning. The main purpose is to develop the quantitative technique of risk analysis for certain stakeholder of project. (Tsai et al. 2001). However, most of the past studies are discussing the project risk from general viewpoint of all stakeholders to build a body of knowledge, but not from the viewpoints of jobsite engineers. Especially, the studies of safety risk management in Japan are still focusing on the contract relation of stakeholders in qualitative discussing.

\section{Methods}

To determine safety-related health, as well as safety climate perception, the selected population in the study was personnel working in several active construction sites in Tabriz, including managers, engineers, supervisors, technicians and workers. The samples were selected randomly among the workers of the target large scale construction sites in Tabriz. The Nordic Occupational Safety Climate Questionnaire (NOSACQ) was used for the survey, consisting of 50 items by which people's attitude to safety-related health at workplace is determined. These questions cover 7 dimensions (factors) of safety and health condition and climate including ability and priority of safety-related health management, power of safety and health management, justice on safety and health management, commitment of all involved workers to safety and health, lack of risk acceptance and priority of safety and health by workers, communication of co-workers with each other and learning the safety and health issues and trust of workers to the efficiency of safety and health systems. The respondents showed their agreement to the questions in four-item Likert scale. Value 1 indicated "total disagreement" and 4 as "total agreement".

To measure the data collected on safety and health management, HSE questionnaire was used. This questionnaire consists of 63 items at five-item Likert scale; value 1 indicating total disagreement and 5 indicating total agreement. Seven parts of this questionnaire included leadership and commitment, strategy, organizing, risk assessment, planning, execution and monitoring and finally audit. The reliability of HSE management questionnaire was secured for more accuracy by Cronbach's alpha coefficient. Total Cronbach's alpha of questionnaire was 0.96 and showed good reliability of the applied HSE management system questionnaire. The questionnaire results were processed in SPSS software, and descriptive statistics as central measures as well as tables and statistical classifications were used. For data analysis (to determine the relationship between quantitative and qualitative variables) Chi-square test and one-way variance analysis (ANOVA) test were used. In this study, 222 questionnaires were distributed 
among respondents, all of respondents were male, and $44.1 \%$ had an education level above Diploma and $72.1 \%$ were married.

Detailed information about characteristics of respondents are shown in Tables 1 to 4 .. Furthermore, ANOVA test and LSD were applied that showed significant relationship between the groups (work experience less than 10 years) and (work experience more than 20 years), with $P$-value $=0.006$ and the groups (work experience less than 10 years) and (work experience 10-20 years) with P-value as 0.04. However, between the scores of safety, health and environment and the number of hours worked per month, marital status, having another or second job, working shift and the time of incident were not statistically significant ( $\mathrm{p}>0.05)$.

Table 1: Frequency of quantitative and qualitative variables.

\begin{tabular}{lcccc}
\hline Variable & Mean & Standard Deviation & Minimum & Maximum \\
\hline Age (year) & 34.17 & 8.75 & 19 & 65 \\
\hline Work experience (year) & 7.64 & 6.42 & 1 & 30 \\
\hline Work hour per month & 214.65 & 51.56 & 80 & 400 \\
\hline Mean safety climate & 3.29 & 0.24 & 2.62 & 3.96 \\
\hline HSE mean & 3.64 & 0.51 & 2.52 & 5 \\
\hline Total scores of safety climate & 164.25 & 12.38 & 131 & 198 \\
\hline HSE sum of squares & 228.09 & 33.25 & 125 & 315 \\
\hline
\end{tabular}

Based on data study of the mean and standard deviation as shown in Table 2, safetyrelated health climate perception among construction workers was achieved in Tables 3 and 4. The one-way analysis of variance (ANOVA) and LSD test were also applied which showed that there was a significant correlation between the safety condition scores, with groups of employees $(p=0.02)$ and the second jobs of employees $(p=0.04)$. However, the mean total scores of safety condition, education, age, work experience, hours worked per month, marital status, having a second job, an accident and work time staff was not statistically significant $(p>0.05)$. Pearson correlation coefficient between the average scores of HSE with safety-related health condition in employees of selected construction sites in Tabriz was 0.335, $(\mathrm{p}=0.001)$.

Table 2: Safety and health sectors

\begin{tabular}{lcc}
\hline Health, Safety and Environment management sectors & Mean Standard & Deviation \\
\hline Leadership & 3.78 & 0.64 \\
\hline Strategy & 3.77 & 0.64 \\
\hline Organization & 3.64 & 0.58 \\
\hline Risk management & 3.8 & 0.71 \\
\hline Planning & 3.37 & 0.64 \\
\hline Execution and monitoring & 3.56 & 0.61 \\
\hline Audit & 3.67 & 0.55 \\
\hline
\end{tabular}

The mean score of safety climate perception among job groups had significant difference. In previous studies, it was stated that planners of safety climate in such a project should consider that in some cases, improvement of safety climate in a special group needs intervention in another group. Thus, in interventions on groups with low 
score of safety climate, considering important factors of such phenomenon should be considered. The results of survey showed that the mean score of HSE management was 3.65 and it is ranging from "No Idea" to "Total Agreement". The element of risk assessment of HSE management system had the highest mean 3.8 which means that assessment of HSE is performed regarding activity, services and development of useful measurements to reduce risk and events at work place. Then leadership and strategy and audit with $3.78 \pm 0.7,3.77 \pm 0.64$, and $3.67 \pm 0.55$ had the highest mean of HSE management system elements. Among HSE management systems and age, marital status, there was no significant relationship in the results of the survey. But, HSE management system had significant relationship between job groups, education and work experienced.

Table 3: Safety dimensions in selected construction sites.

\begin{tabular}{lccc}
\hline Safety climate dimensions & $\begin{array}{c}\text { Number } \\
\text { of items }\end{array}$ & Mean & $\begin{array}{c}\text { Standard } \\
\text { Deviation }\end{array}$ \\
\hline Ability and priority of management & 9 & 3.28 & 0.34 \\
\hline Power of safety management & 7 & 3.30 & 0.4 \\
\hline Justice of safety management & 6 & 3.26 & 0.35 \\
\hline Commitment of workers to safety issues & 6 & 3.14 & 0.37 \\
\hline Lack of acceptance of risk and priority to safety by workers & 7 & 3.56 & 0.5 \\
\hline $\begin{array}{l}\text { Communication of co-workers with each other and learning } \\
\text { safety issues }\end{array}$ & 8 & 2.89 & 0.27 \\
\hline Trust of workers to effectiveness of safety systems & 7 & 3.65 & 0.44 \\
\hline
\end{tabular}

Table 4: Safety perception working groups.

\begin{tabular}{lccc}
\hline Dimensions of safety climate & Engineering & Administrative & $\begin{array}{c}\text { Servant, operator, } \\
\text { technician }\end{array}$ \\
\hline Ability and priority of management & 3.22 & 3.27 & 3.32 \\
\hline Power of safety management & 3.15 & 3.35 & 3.38 \\
\hline Justice of safety management & 3.17 & 3.17 & 3.33 \\
\hline Commitment of workers to safety issues & 3.10 & 3.01 & 3.2 \\
\hline $\begin{array}{l}\text { Lack of acceptance of risk and priority of } \\
\text { safety by workers }\end{array}$ & 3.51 & 3.44 & 3.63 \\
\hline $\begin{array}{l}\text { Relationship of coworkers with each other } \\
\text { and learning safety issues }\end{array}$ & 2.84 & 2.93 & 3.91 \\
\hline $\begin{array}{l}\text { Trust of workers to effectiveness of safety } \\
\text { systems }\end{array}$ & 3.57 & 3.73 & 3.67 \\
\hline
\end{tabular}

\section{Discussion}

To improve safety and health system of a construction site, improvement of safety-related health systems and periodical evaluations are necessary (Basiri, 2017). The results of survey showed that the perception of personnel health, safety and environment had no special association with age, work experience, education. The score of safety climate among age, work experience and education showed no significant difference. The study in (Adl et al., 2011) had already showed that education and work 
experience had no significant relationship with any of the dimensions of safety-related health climate perception. The study also showed that of safety and health climate dimensions, safety and health management power had significant relationship with job group and education and it showed that engineers with higher education based on different managerial positions and safety and health management had high power in creating safety and health climate. Another dimension of safety and health climate is non acceptance of risk and prioritization of safety and health as associated with age and work experience and based on the young participants and no higher experience, safety-related health issues are not considered well and prioritization of safety-related health issues are considered not to be vital.

\section{Conclusion}

This study focused on the main aspects of safety-related health management and perception of safety and health climate in large scale construction sites. Selected workers from a number of construction companies active (large scale projects) in Tabriz, Iran were randomly selected to answer the NOSACQ questionnaire. The collected data were analyzed using SPSS software, and the results were classified in detailed and further discussed. The study results showed that safety and health management in selected construction sites were relatively acceptable. Furthermore, the results showed that the safety-related health perception of construction personnel had no special association with their age, work experience and education level. However, it was found that the creation of a safety and health climate in large scale construction sites heavily depends on the approach of people responsible in higher ranks of the organizational hierarchy, including managers and engineers with higher education and organizational position.

For the time being, modern development in urban domains have been facing problems regarding sustainability, and alternative plans have been sought (Moosavi, 2016). Generally speaking, lack of skilled personnel is usually considered a major barrier to the effective implementation of safety-related health in construction projects in Iran. This view is further supported by several previous studies that have identified insufficient enforcement among the challenges to effective regulation and enforcement in construction projects. In a similar vein, some researchers have stated that an insufficient number of competent occupational health services hinders the development of occupational health services in construction projects in developing countries.

Consequently, implementation of safety legislation requires funds to be available for effective provision of adequate facilities and recruitment of training officers who enforce the laws. However, some researchers and managing authorities argue that the number of technical infrastructure is inadequate, which hinders the implementation of safety and health legislation in Iran.

\section{References}

Adl, J., Jahangiri, M. Rismanchian, M., Marioryad, H. Karimi, A. \& Ghaderi, M. R. (2011). Evaluation of safety climate in a steel-manufacturing plant. Journal of School of Public Health and Institute of Public Health Research, Vol. 9, No. 1, pp. 23-34. 
Basiri, M. (2017). Evaluation of construction projects by criteria of sustainable development. Iranian Online Journal of Urban Research, 2(2), 1-4.

Han Ahn, Y., Woo Jung, Ch., Suh, M., \& Hwa Jeon, M. (2016). Integrated construction process for green building. International Conference on Sustainable Design, Engineering and Construction, Procedia Engineering, 145 ( 2016 ) $670-676$.

Larsson, N. (2009). Integrated Design Process: Theory, History, Demonstrations. [cited 2015 April 1]; Available from: http://www.iisbe.org/node/88.

Rajendran, S., \& Gambatese, J.A. (2009). Development and initial validation of sustainable construction safety and health rating system. Journal of Construction Engineering and Management, 135 (10), 10671075.

Roodman, D.M. \& Lenssen, N. (1995). A building revolution: how ecology and bealth concerns are transforming construction. Washington DC: Worldwatch Institute.

Tsai, T.C., Furusaka, S. and Kaneta, T. (2001), Development of decision support system of risk management in construction phase of construction projects. Journal of Architecture, Planning and Environmental Engineering, AIJ, No. 549, pp.239-246.

Moosavi, M. S. (2016). New methodologies of education and research in urban studies. Iranian Online Journal of Urban Research, 1(1), 1-5.

Verburg, R.M., Bosch-Sijtsema, P., \& Vartianien, M. (2013). Getting is done: critical success factors for project managers in virtual work settings. International Journal of Project Management, 31, 68-79. 